\title{
Erratum to: Unusual traumatic spondyloptosis causing complete transection of spinal cord
}

\author{
S. H. Chandrashekhara ${ }^{1,2} \cdot$ A. Kumar $^{1} \cdot$ S. Gamanagatti ${ }^{1}$ - K. Kapoor ${ }^{1}$. \\ A. Mukund ${ }^{1} \cdot$ D. Aggarwal ${ }^{3} \cdot$ S. Sinha ${ }^{3}$
}

Published online: 6 April 2017

(C) SICOT aisbl 2017

Erratum to: International Orthopaedics (SICOT)

Doi 10.1007/s00264-010-1190-6

The original version of this article inadvertently contained mistake.

In the title and article "Unusual traumatic spondyloptosis causing complete transaction of spinal cord", the term "transaction" should actually be "transection".

The online version of the original article can be found at http://dx.doi.org/ $10.1007 / \mathrm{s} 00264-010-1190-6$

$\triangle$ S. H. Chandrashekhara drchandruaiims@yahoo.com

1 Department of Radio-diagnosis, JPN Apex Trauma Centre, All India Institute of Medical Sciences, New Delhi, India

2 Department of Radiology, All India Institute of Medical Sciences, New Delhi 110029, India

3 Department of Neurosurgery, JPN Apex Trauma Centre, All India Institute of Medical Sciences, New Delhi, India 